Revista de Dialectología y Tradiciones Populares, vol. LXXII, n. ${ }^{\circ}$ 1, pp. 51-57, enero-junio 2017 , ISSN: 0034-7981, eISSN: 1988-8457, doi: 10.3989/rdtp.2017.01.001.06

\title{
Espacios migrantes y nuevos movimientos sociales: el caso de Marea Granate
}

\author{
Migrant Spaces and New Social Movements: \\ The Case of Marea Granate
}

\author{
Eduard Ballesté Isern ${ }^{1}$ \\ Universitat de Lleida
}

\section{RESUMEN}

El movimiento de los indignados en España coincidió con el auge de la emigración juvenil española debido a la crisis. En este artículo se analizará el caso de Londres, donde la comunidad española creó un movimiento que les permitiera unirse a la lucha iniciada en España: el 15-M Londres, el cual se convirtió en Marea Granate Londres para poder dar cabida a más gente emigrada a la capital británica. A partir del análisis del movimiento pretendemos debatir su naturaleza: ¿es transnacional o es una expresión en el exterior de un movimiento puramente nacional?

Palabras clave: Movimientos sociales; Transnacionalismo; Internacionalismo; Emigración.

\section{SUMMARY}

The 'Indignados' or Indignant movement in Spain took place when part of Spanish society was leaving the country due to the economic crisis. This article will analyze the case of London, where the Spanish community created a movement in order to be part of the fight that was going on in Spain: 15-M London; which became Marea Granate London in order to welcome more people. After analysing how the movement is organised, we will consider whether Marea Granate London is a transnational movement or an international expression of a national movement.

Key words: Social Movements; Transnationalism; Internationalism; Migration.

\footnotetext{
${ }^{1}$ Correo electrónico: Eballeste@geosoc.udl.cat. ORCID ID: http://orcid.org/0000-0001-6757-9959.
} 


\section{INTRODUCCIÓN}

La ocupación pública indignada que se produjo el mayo de 2011 en España permitió visibilizar una nueva "cara" de la juventud, políticamente comprometida e inconformista, que durante mucho tiempo había sido categorizada en su globalidad como Ni-Ni's (Navarrete 2011; Feixa et al. 2015). En esa aparición pública se puso encima del tablero la necesidad de hacer visible y patente un nuevo escenario de no futuro para toda una generación. La aplicación de reiteradas políticas de austeridad junto con un modelo productivo y ocupacional que no se mantenía acorde a las aspiraciones vitales y formativas con las que se había criado dicha juventud, mostraban un modelo en crisis que seguía castigando especialmente a los más jóvenes (Valenzuela 2015), materializándose en un paro juvenil creciente que parecía enquistarse y no revertir y un aumento de la precarización de los lugares de trabajo a los cuales podían acceder (Beck 2000; Standing 2013).

En medio de esta crisis estructural, una parte de estos jóvenes optaron (y siguen haciéndolo) por emigrar como estrategia para hacer la transición a la vida adulta. Juventud Sin Futuro, uno de los colectivos pioneros del 15-M en España, ya ponía de manifiesto bajo la campaña No nos vamos, nos echan la "expulsión" que sufren algunos jóvenes que se ven enviados al exilio como consecuencia principal de las políticas de austeridad aplicadas en este periodo. Es en este marco de emigración donde aquellos jóvenes pueden encontrar en los movimientos sociales en el exterior un espacio donde poder hacerse visibles, reivindicar su situación y donde, en última instancia, poder articular una respuesta colectiva hacia las necesidades de los emigrantes.

Este estudio se centra en el análisis etnográfico sobre la Marea Granate Londres (MG Londres) entre 2013 y 2016², el cual nos ha permitido profundizar en el análisis de dicho movimiento y buscar marcos teóricos que nos sirvan para poder comprenderlo y situarlo de forma más clara en el plano de las teorías sobre movimientos sociales. En ese sentido, se ha analizado el grado de internacionalización del propio movimiento y comparado con otros movimientos anteriores para ver qué función ejerce entre los jóvenes emigrantes y así discernir si se trata de un movimiento transnacional o de una expresión de movimiento nacional en el exterior.

\section{APUNTES SOBRE LA INTERNACIONALIZACIÓN DE LOS MOVIMIENTOS}

Las teorías sobre internacionalización y el transnacionalismo de los movimientos sociales surgen a finales del siglo XX con diferentes trabajos que estudian el componente, a la vez local y global, de los movimientos contestatarios. Así, con el EZLN en México se vive el comienzo de los que vendrían a ser movimientos locales con un impacto global, donde por primera vez las reivindicaciones se manifestaron a través de muestras de solidaridad y de movilización alrededor del mundo. De este modo,

\footnotetext{
${ }^{2}$ El trabajo de campo, a cargo de Clara Rubio, ha consistido en asistir a asambleas, actos y movilizaciones, así como realizar entrevistas en profundidad a algunos de los participantes de la Marea Granate Londres.
} 
juntamente con el aumento y la mejora de las redes de comunicación global, se ponían las bases de lo que buscaría establecerse como un proceso global alternativo al modelo neoliberal imperante, el cual ponía de manifiesto la necesidad de repensar un nuevo modelo que, superando la libre circulación de las mercancías y flujos económicos, pusiese en el centro del debate cuestiones como la alteridad cultural, la justicia social, el pacifismo, el ecologismo o la libre circulación de personas (Juris et al. 2012).

Este proceso ha tenido distintos momentos clave que lo escenifican de forma diáfana como los Foros Sociales Mundiales, las movilizaciones contra la Guerra de Iraq o, más recientemente, el proceso de indignación que recorrió buena parte del planeta en 2011. Todos ellos tenían una perspectiva global en su oposición a problemáticas supranacionales y un interés de contestación frente a acontecimientos locales (Pleyers 2013). Este proceso, lejos de superar definitivamente las barreras nacionales, supuso una conjugación de problemáticas globales que utilizaban espacios nacionales para sus marcos de protesta y, a menudo, para sus objetivos de lucha (Tarrow 2012). Como muy bien sugiere Tilly (2010), las divisiones históricas que se producían en cuanto a las reivindicaciones de los movimientos contestatarios permitían situarlos en una misma escala. Era posible establecer cómo aquellas reivindicaciones locales tenían como objetivo de sus luchas órganos locales; las nacionales, otros de carácter estatal; y las globales, órganos internacionales. El cambio se produce cuando dichas dicotomías escalares se tornan difusas y difíciles de distinguir pudiendo con eso observar movilizaciones que se establecen en distintas escalas "geográficas".

Durante las movilizaciones que tuvieron lugar en todo el planeta el año 2011, las redes jugaron un papel clave (Castells 2012). El hecho de encontrarse muchos de los actores conectados en la red provocó una alternancia "geográfica" entre el espacio urbano (donde el movimiento se materializaba) y el virtual (donde el movimiento, autónomo, buscaba crecer y expandirse). Esto les permitió al mismo tiempo ser locales y globales, ubicándose en un espacio urbano determinado (las acampadas) y actuando contra ciertas políticas municipales, regionales y nacionales; a la vez que les daba un impacto y una solidaridad con otros movimientos globales vía internet. Como explican Juris et al. (2012), estos "novísimos" movimientos sociales vivirían a caballo entre el espacio físico y el virtual, haciéndose así muy presentes entre la población juvenil.

Este marco descriptivo nos permite entender la evolución reciente de los movimientos sociales hasta llegar a los protagonizados en 2011. Consecutivamente, durante el "post-15-M", surgieron diferentes movimientos más específicos y localizados que vinieron a mostrarse como consecuencia directa del movimiento indignado (Mansilla 2015), como las mareas o las plataformas reivindicativas a favor de los servicios públicos y en contra las políticas de austeridad.

\section{MG LONDRES: ORÍGENES Y FUNCIONAMIENTO}

La MG Londres tiene sus orígenes en el surgimiento del 15-M en España, cuando algunos de los emigrantes españoles que residían en la ciudad se encontraron de manera espontánea delante de la Embajada Española en Londres el mismo día 16 de 


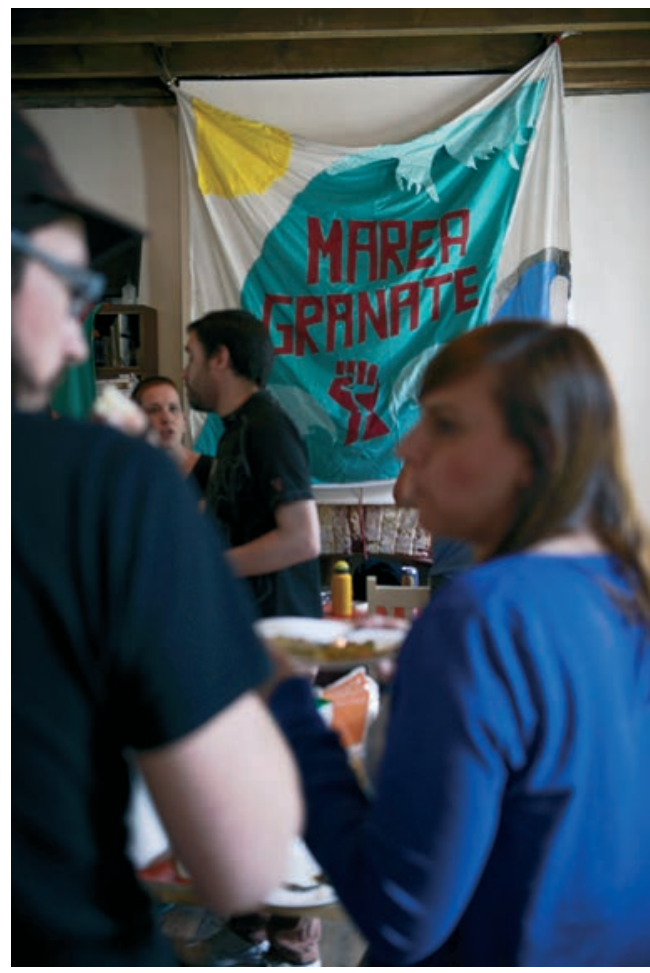

IMAGEN 1.-Activistas durante el Segundo Aniversario de Marea Granate. The Field (Londres), 30 de mayo de 2015. Fotografía de Marta M. Vilela.

mayo de 2011. La concentración se dio, así como en las otras ciudades del territorio español, a raíz de la noticia de la evacuación por parte de la policía de los activistas que acamparon en Madrid el día 15 de mayo.

El día 19 de mayo uno de los informantes, Santi ${ }^{3}$, recibe por Twitter una fotografía de la acampada en Londres y decide sumarse. El activista, explica, se traslada a la Embajada pensando que habrá poca gente, pero por sorpresa al llegar encuentra unas 200 personas gritando y manifestándose. La concentración culmina cuando uno de los asistentes propone hacer la primera asamblea del 15-M Londres. Esta primera asamblea decide acampar durante todo el fin de semana, sin ninguna infraestructura, organización, ni permiso, de una manera totalmente espontánea, pero poco a poco todo el mundo empezó a contribuir para su buen funcionamiento.

Fue pasados dos años, en el segundo aniversario del movimiento, cuando 15-M Londres se convirtió en MG. Durante este segundo aniversario decidieron volver a acampar delante de la Embajada coincidiendo justamente con el surgimiento de todas las mareas a nivel español. Como explica Santi, "medio en serio medio en broma, dijimos cuál sería el color de la marea de los emigrantes y fue así que dándole vueltas, a las 3 o 4 de la mañana llegamos a la conclusión de que podría ser MG por el color del pasaporte" (Santi, 31 de marzo de 2015, Southbank Centre). En el caso de Londres el nombre oficial es MG$15 \mathrm{M}$ Londres ya que no quisieron perder los orígenes del movimiento. La principal razón de este cambio de nombre fue la voluntad de ser más inclusivos hacia la comunidad española en Londres, creando un espacio donde emigrantes que no confluyeran con la filosofía del 15-M también pudieran tener cabida. De hecho, desde el movimiento se detectó que debido a que la imagen mediática que se había creado en España sobre el movimiento 15-M lo representaba como "muy radical", cambiarle el nombre permitía su apertura hacia la comunidad española en Londres.

Los objetivos de MG Londres son, de acuerdo con lo explicado por Santi: crear una red de solidaridad entre la comunidad española en Londres, sensibilizar a españoles en Londres sobre la situación política en España, dar voz a los emigrantes, or-

\footnotetext{
${ }^{3}$ Activista de 41 años, originario de las islas Canarias, que ha vivido en Londres entre 2008 y 2016 .
} 
ganizar espacios de debate y llevar a cabo acciones sociopolíticas. Además, se trata de un movimiento que está integrado en la capital británica y que ha colaborado con otras organizaciones en diferentes acciones o campañas, como por ejemplo con otros movimientos sociales de inmigrantes del Mediterráneo, con movimientos alterglobalización británicos (Occupy London) y con otras asociaciones culturales y sociales en Londres (The Field).

Así pues, una vez convertido en MG Londres, el movimiento continuó llevando a cabo acciones y debates en torno a temas que afectaban a la política y a la sociedad española con el objetivo de luchar conjuntamente contra las causas y consecuencias de la crisis financiera y otras cuestiones de la agenda española, siguiendo así con las luchas que promovía el 15-M. Al mismo tiempo, también quisieron incorporar a sus objetivos la lucha por los derechos de los españoles como emigrantes, como el derecho a votar desde el extranjero (campaña "Voto Rogado"), la defensa de sus derechos como trabajadores inmigrantes (aspecto trabajado desde el grupo "Oficina Precaria"), o la creación de una lista del "Consejo de Representantes Emigrados" para poder tener representación dentro del Consulado Español en Londres (grupo de trabajo CRE). Santi, que estuvo presente desde el inicio del movimiento, explica que MG Londres fue la primera iniciativa a nivel mundial, la cual se fue difundiendo internacionalmente hasta llegar a ser 35 nodos. Estos se organizan virtualmente a través de la plataforma "Mumble" ${ }^{4}$ donde llevan a cabo asambleas en las que participan todos los nodos.

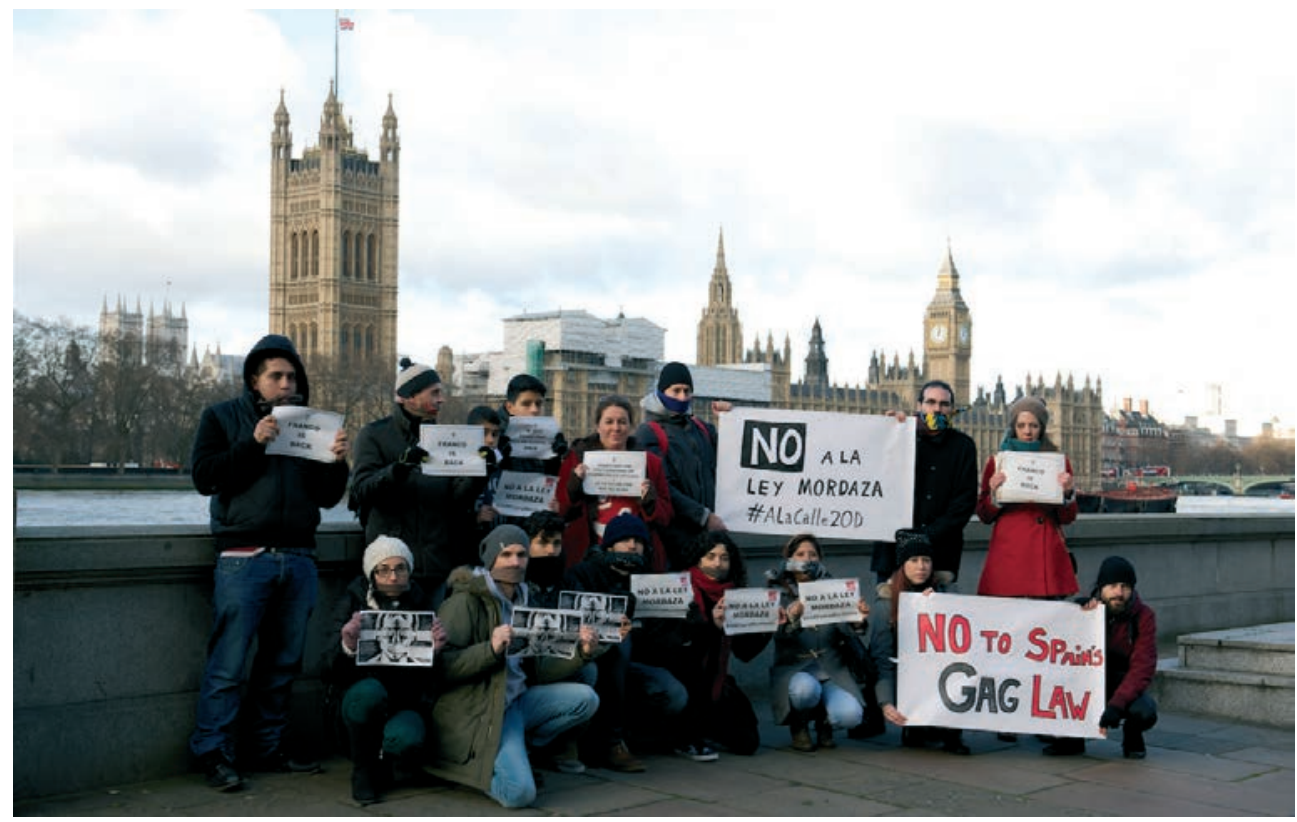

Imagen 2.-Acción de Marea Granate Londres contra la Ley Mordaza. Fotografía de Marta M. Vilela.

\footnotetext{
${ }^{4}$ Mumble es una plataforma online que permite conectar personas de todo el mundo al mismo tiempo para hacer debates.
} 
De manera general, MG Londres está estructurada en tres ramas: las asambleas generales, donde se deciden elementos organizativos del movimiento; las asambleas temáticas, donde los activistas se reúnen para debatir temas sociales de interés (como el decrecimiento o la renta social básica); y las acciones, que son las actividades que el propio movimiento desarrolla. Las acciones pueden ser como copia de una movilización en España, como fue la Marcha para la Dignidad del 22 de marzo de 2015; acciones organizadas con otros nodos internacionales, como fue la acción conjunta que se hizo en torno a la Ley Mordaza; o acciones que MG Londres organiza de manera individual, como la movilización a favor de la III República cuando el rey Juan Carlos I abdicó el día 2 de junio de 2014. Además, el movimiento está formado por otros grupos más pequeños que integran intereses concretos, como la Asamblea de Mujeres, la Asamblea de Masculinidades o la Oficina Precaria, que da asesoramiento laboral a emigrantes españoles en Londres.

Uno de los eventos analizados es la celebración del Segundo Aniversario de MG Londres el día 30 de mayo de 2015 en The Field. La celebración duró todo el día. Por la mañana se hizo una asamblea organizativa, posteriormente se hizo una comida y por último se hizo una asamblea temática donde se analizaron los resultados de las elecciones municipales del 24 de mayo. Durante la asamblea de la mañana hubo una asistencia aproximada de 25 personas, la cual se multiplicó durante la asamblea temática. Asimismo, la asistencia fue muy superior cuando se hablaron de temáticas relacionadas con la situación de la política española y no sobre temas de organización del movimiento. No obstante, esta diferencia es aún más notoria si se tienen en cuenta otras acciones puntuales, como el caso de la movilización por la III República cuando el rey Juan Carlos abdicó el 2 de junio de 2014, momento en que el movimiento reunió unas 300 personas delante de la Embajada española en Londres.

\section{MG: EMIGRACIÓN DE UN MOVIMIENTO}

Para comprender la creación y evolución del movimiento aquí estudiado, la MG Londres, es necesario observar el proceso paralelo que se vivió en el estado español de nacimiento de las distintas mareas. Los grupos de trabajo específicos que se generaron en las plazas del 15-M —en torno a los efectos de los recortes en los servicios públicos, las problemáticas de vivienda o los problemas de los jóvenes durante la crisis- se materializaron en mareas o colectivos que buscaban profundizar en dichas luchas. En ese sentido, la MG (y específicamente para nuestro caso la de Londres, la primera en aparecer en el año 2013), sigue los mismos ritmos y procesos que los movimientos post-15-M en el estado español. El movimiento, con la conversión que hizo hacia MG, buscó centrar las luchas hacia temas específicos del proceso migratorio: el derecho a voto en la distancia, la denuncia de los motivos "reales" de la emigración o la creación de un espacio de apoyo mutuo entre los recién llegados a la ciudad.

En ese sentido, es preciso observar la MG como una ramificación del propio movimiento indignado, que siguió el mismo camino que las distintas mareas estaban elaborando en España. Es interesante indagar en las especificidades de este movimiento que lo sitúan entre la autonomía de un movimiento en el exterior y las fuertes vincu- 
laciones con las dinámicas de los movimientos "hermanos" en el país de origen. Estas especificidades se ven reflejadas muy claramente en la tipología de actividades que desarrollan: algunas de ellas como respuesta a eventos ocurridos en España, otras vinculadas a la sociedad británica y otras que responden a una demanda mundial. No obstante, tal y como se ha podido observar en el trabajo de campo y a partir de las entrevistas con los activistas, las actividades con más quorum fueron aquellas que respondían a una petición hacia el estado español.

De este modo, estamos ante un movimiento que se manifiesta a nivel internacional a través de sus nodos y que, siguiendo las definiciones de movimiento transnacional, trasciende las fronteras de estado con su movilización a nivel internacional. No obstante, MG encaja mejor en la definición de movimiento nacional español en el extranjero desde que su principal acción (así como también la más compartida para la comunidad española) está focalizada en el estado español y no tanto a nivel supranacional.

\section{BIBLIOGRAFÍA CITADA}

Beck, Ulrich. 2000. Un Nuevo Mundo Feliz: la precariedad del trabajo en la era de la globalización. Barcelona: Paidós.

Castells, Manuel. 2012. Redes de indignación y esperanza. Los movimientos sociales en la era internet. Madrid: Alianza.

Feixa, Carles, María Àngels Cabasés y Agnès Pardell. 2015. «El juvenicidio moral de los jóvenes... Al otro lado del charco", en José Manuel Valenzuela (coord.), Juvenicidio. Ayotzinapa y las vidas precarias en América Latina y España: 235-269. Barcelona: NED Ediciones.

Juris, Jeffrey, Carles Feixa e Inés Pereira. 2012. "La globalización alternativa y los "novísimos" movimientos sociales". Revista del Centro de Investigación. Universidad La Salle 10(37): 23-39.

Mansilla, José Antonio. 2015. “Movimientos sociales y apropiaciones colectivas en la Barcelona post15M: el papel de la Assemblea Social del Poblenou». Etnográfica 19(1): 77-97.

Navarrete, Lorenzo. 2011. Desmontando a ni-ni. Un estereotipo juvenil en tiempos de crisis. Madrid: INJUVE.

Pleyers, Geoffrey. 2013. Alter-Globalization: Becoming Actors in the Global Age. Cambridge: Polity books.

Standing, Guy. 2013. El Precariado: una nueva clase social. Barcelona: Ediciones de Pasado y Presente.

Tarrow, Sidney. 2012. El Poder en Movimiento: los movimientos sociales, la acción colectiva y la política. Madrid: Alianza.

Tilly, Charles. 2010. Los movimientos sociales, 1768-2008: desde sus origenes a Facebook. Barcelona: Crítica.

Valenzuela, José Manuel. 2015. El sistema es antinosotros. Culturas, movimientos y resistencias juveniles. Tijuana: El Colegio de la Frontera Norte. 